\title{
Notes on the vocalizations of Stripe-cheeked Bulbul (Andropadus milanjensis)
}

\section{Peter Boesman}

In the following we briefly analyze and compare voice of the three races of Stripe-cheeked Bulbul (Andropadus milanjensis). We also try to quantify the extent of any vocal differences using the criteria proposed by Tobias et al. (2010), as a support for taxonomic review. We have made use of sound recordings available on-line from Xeno Canto (XC) and Macaulay Library (ML).

A comparison of vocalizations per race with sonograms:

striifacies

\section{Song:}

Taita hills, Kenya

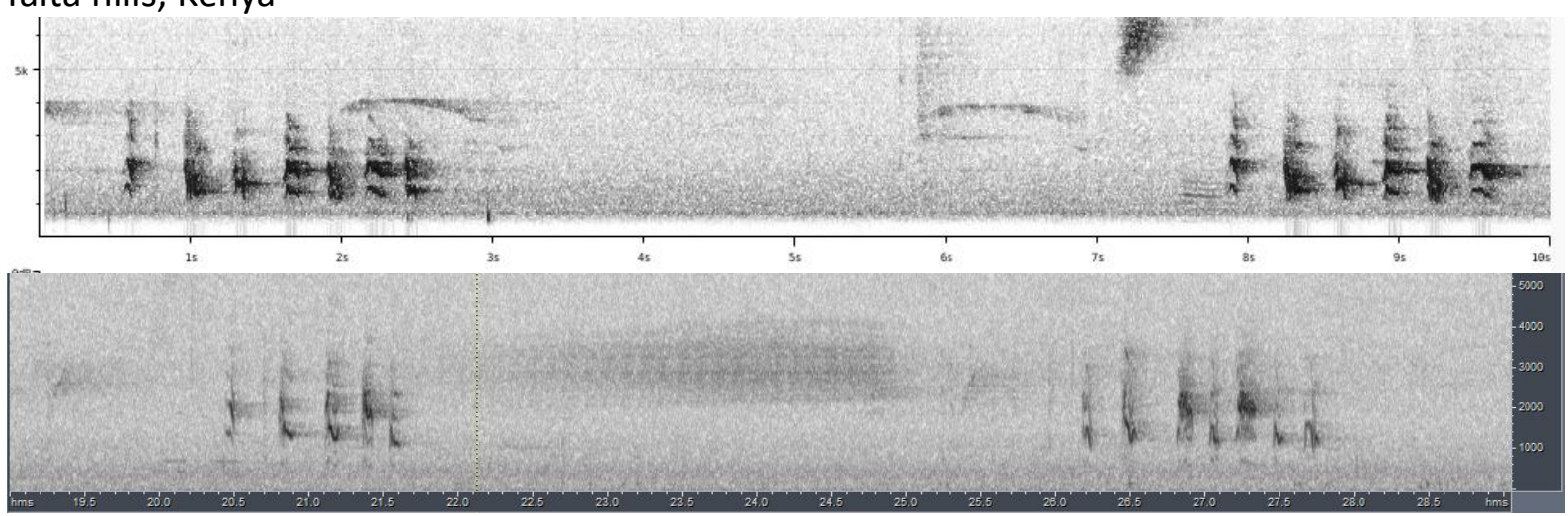

N Tanzania



C Tanzania

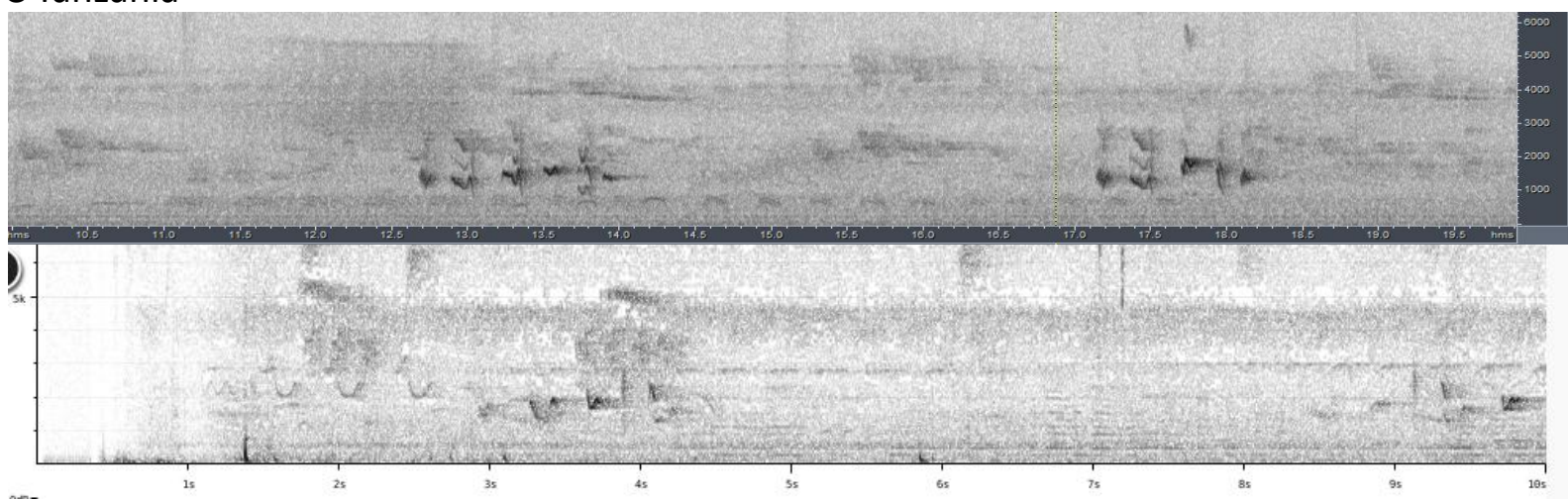


HANDBOOK OF THE

BIRDSPFPIE WORLD ORNITHOLOGICAL NOTES

\section{Alternative song:}

Taita hills, Kenya

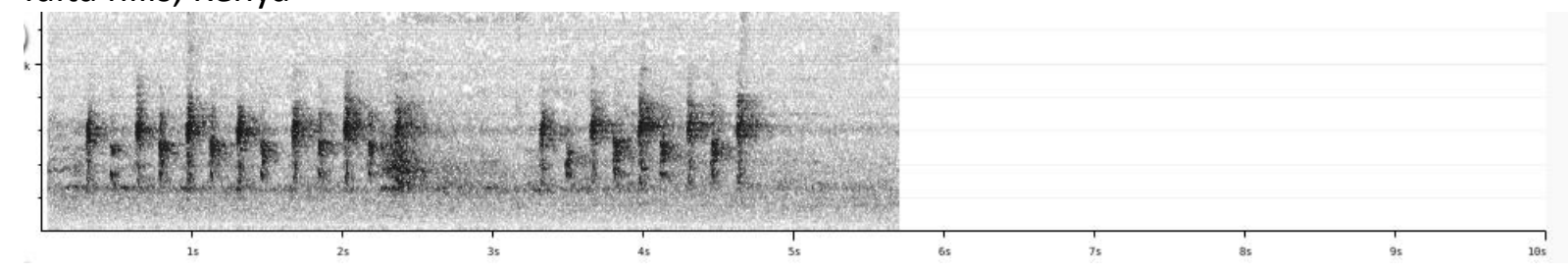

\section{N Tanzania}

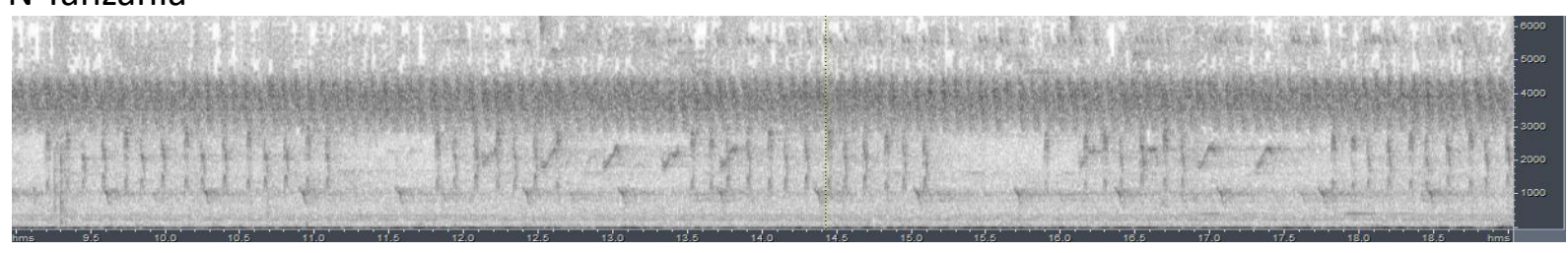

\section{olivaceiceps}

\section{Song:}



milanjensis

Song:

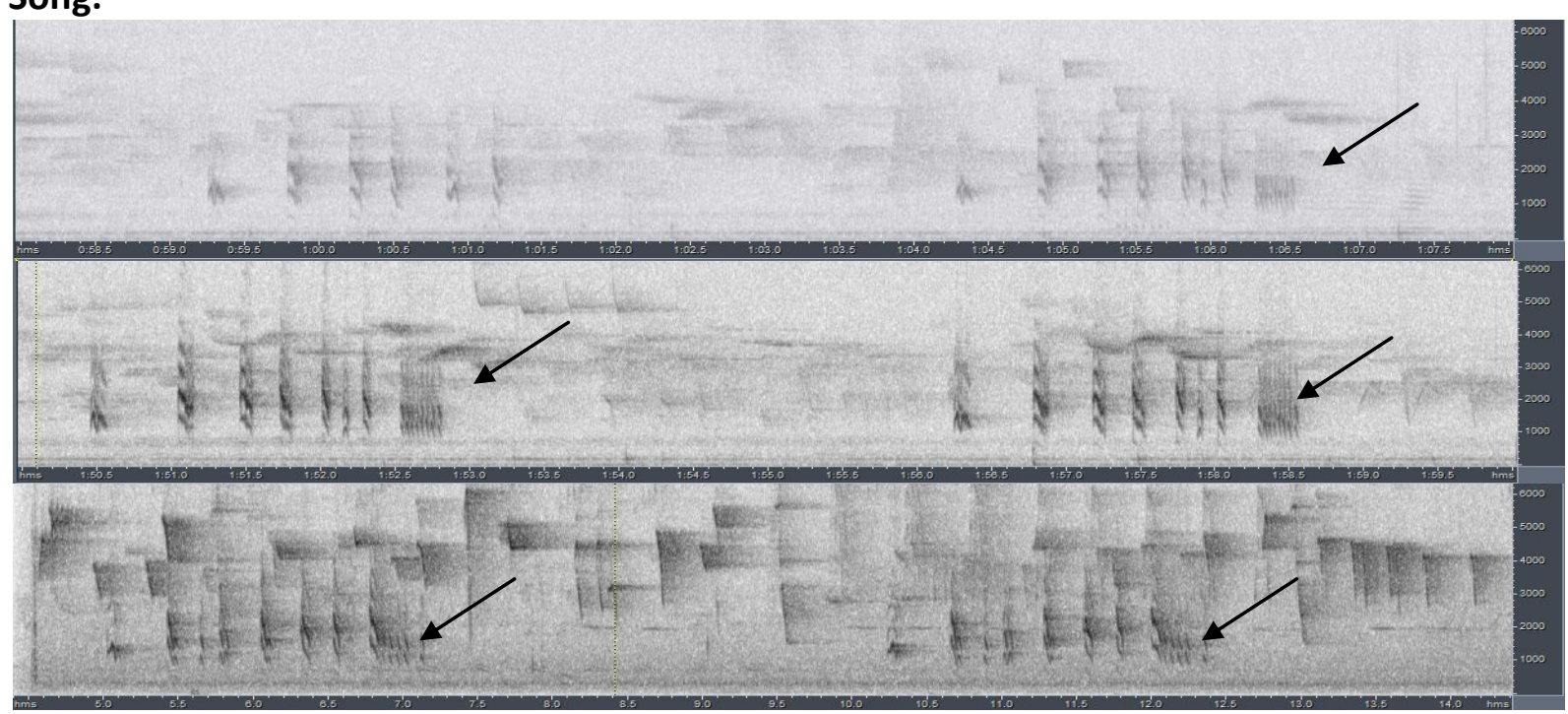





From the above examples, for striifacies, there seems to be a distinct difference between the nasal voice in the Taita Hills and the more melodious notes in $\mathrm{N}$ and $\mathrm{C}$ Tanzania. Also the alternative song is seemingly different.

Example 3 of striifacies ( $\mathrm{N}$ Tanzania) and example 1 of olivaceiceps sound very similar, with about the same rhythmic delivery. An alternative song is not documented for olivaceiceps, but there are very few recordings of this taxon anyway.

milanjensis is again more nasal sounding (same vocal quality as striifacies birds from Taita Hills), but song mostly ends with a trill (see arrows on sonograms).

Given that at least some songs of olivaceiceps and striifacies seem to be indistinguishable, one could only give a vocal score for the apparent unique alternative song of striifacies, but this is then by assuming this is absent in olivaceiceps, which given the few available recordings, is rather hypothetical.

Song of milanjensis is the most distinctive, and can be easily identified whenever the final trill is uttered. Besides that, it comes very close to song of striifacies from Taita hills. A tentative vocal score of 2-3 vs. olivaceiceps and 1-2 vs. striifacies seems likely based on the limited number of available recordings, but should be confirmed by more recordings.

Further study of the different populations of the race striifacies is also recommended.

This note was finalized on 18th February 2016, using sound recordings available on-line at that moment. We would like to thank in particular the sound recordists who placed their recordings for this species on XC and ML: Jason Anderson, Louis Hansen, Linda Macaulay, Hans Matheve, Carolyn McBride, David Moyer, Bram Piot and Keith Stuart.

\section{References}

Tobias, J.A., Seddon, N., Spottiswoode, C.N., Pilgrim, J.D., Fishpool, L.D.C. \& Collar, N.J. (2010). Quantitative criteria for species delimitation. Ibis 152(4): 724-746.

\section{Recommended citation}

Boesman, P. (2016). Notes on the vocalizations of Stripe-cheeked Bulbul (Andropadus milanjensis). HBW Alive Ornithological Note 241. In: Handbook of the Birds of the World Alive. Lynx Edicions, Barcelona. (retrieved from http://www.hbw.com/node/932238 on 30 September 2016). 